Editorial

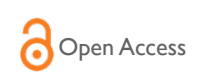

A) CrossMark

\title{
Why do you have to be with us
}

\section{Editorial}

We know that you are doing great science. We know that you want to get it published. We know that your work is creative. We know that the creative work is hard to be perfect. We know that the imperfect work is hard to publish. We know that creative work can't wait. This is why you have to be with us. We publish creative work before it becomes perfect, before it is well accepted. This is the vision of the journal.

Classically defined good journals only publish papers of creative works with substantial and almost all possible circumstantial evidences to support. But by definition, creative work belongs to very few pioneers with vision. The most basic nature of creative work is its imperfection at the early stage. It may be only an idea, reasoning, a strategy. It may lack methods or data to be fully supported. In stone age, you may keep the secret one hundred years until you find all the proofs you need, before you publish it. But now, at information age, you cannot keep your treasure on a treasure island anymore. Information is leaking anyway even your computer or your email is not hacked. And your great idea is so easily to be disseminated via blogs, twitter, wechat and other means you and I never heard of, instead of phone call and conference in the Dark Age. There is no way to track when and how and to whom your idea is gone even you have two-dimensional bar code minted on it.

The only safe way is to publish is as early as possible, even it is immature, even it is only a very preliminary experiment, or even it is only an idea.
Volume I Issue 4 - 2014

Youhe Gao

Department of Pathophysiology, Chinese Academy of Medical Sciences, China

Correspondence: Youhe Gao, National Key Laboratory of Medical Molecular Biology, Department of Pathophysiology, Institute of Basic Medical Sciences, Chinese Academy of Medical Sciences/Peking Union Medical College, 5 Dong Dan San Tiao, Beijing 100005, China, Tel 8610652I2284, Fax 8610652 I2284, Email gaoyouhe@pumc.edu.cn

Received: September 17, 2014 | Published: September 18, 2014

Here is this journal (MOJ Proteomics \& Bioinformatics) we created for you. This is why you have to be with us, for the sake of your invaluable creative idea, for the sake of science.

\section{Acknowledgements}

This work was supported by the National Basic Research Program of China (2012CB517606, 2013CB530805), the Key Basic Research Program of China (No. 2013FY114100), and the 111 Project (B08007).

\section{Conflict of interest}

The author declares no conflict of interest. 